\title{
Facilitating Academic and Mental Health Resilience in Students with a Learning Disability
}

\author{
Lisa Piers, Cheryll Duquette \\ University of Ottawa
}

\begin{abstract}
This qualitative study explored the educational journeys of five postsecondary students with learning disabilities (LD) from the perspective of the students and their families. Using a resilience lens, it examined the challenges that they faced and the capacities and resources that facilitated their resilience and helped them achieve their current level of academic achievement and mental health. A retrospective, multiple case study design was used, and a series of three interviews was conducted with each university student with an LD and their families. The participants identified a number of interactions among the students and their parents, teachers, and peers that helped shape and develop the capacities they needed in order to negotiate for the supports and resources that sustained their well-being. These capacities included an awareness and acceptance of their LD and themselves as learners, the self-advocacy skills they needed in order to seek out and negotiate for the supports and accommodations that would help them succeed, the ability to set lofty yet attainable goals, the perseverance to work toward these goals in spite of setbacks and challenges, and the willingness to use the supports and resources that were available to them.
\end{abstract}

Children diagnosed with a learning disability (LD) comprise the largest category of students with special needs in Canadian schools, representing over half of all pupils with exceptionalities or almost 5\% of all school-age children (APA, 2014; LDAC, 2007). In addition to the academic challenges that they face, many students with an LD also contend with a variety of social and emotional issues brought on by the demands of their 
environments. Over the past several decades, researchers have identified a range of mental health issues that affect students with an LD at a higher rate than their peers, such as anxiety, depression, and even suicidality (Bender, Rosenkrans, \& Crane, 1999; Huntington \& Bender, 2001; Wilson, Deri Armstrong, Furrie, \& Walcot, 2009).

While there is a general acknowledgment that students with an LD are at an increased risk for these kinds of challenges, every child responds differently, and some seem to demonstrate more positive outcomes than others. Resilience research has shown that a number of capacities and resources facilitate positive development and may have the potential to mitigate the impact of an LD on academic development and mental health (Raskind, Goldberg, Higgins, \& Herman, 2002; Werner, 1993). While the number of studies is growing in this area, relatively few have examined these questions from a family perspective. To deepen our knowledge about the experience of having an LD, multiple perspectives should be considered, and more attention needs to be given to the interactions that take place among individuals with an LD, their families, and their environments as they are growing up. The purpose of this research, therefore, was to examine the lived experiences of five postsecondary students who had been diagnosed with an LD and those of their families in order to identify the capacities and resources that helped them on their educational journeys. The aim was to gain a deeper understanding of the complex realities of students with an LD from the point of view of those living through it - the students themselves and those who were closest to them (Schram, 2006). Including the families in the study allowed multiple voices and perspectives to be heard so that a richer, more detailed picture could emerge. We were particularly interested in understanding how individual and environmental capacities and resources could facilitate the academic and mental health development of students with an LD.

\section{Review of the Literature}

While many students with an LD and their families contend with a range of academic and mental health issues, there are those students who seem to cope much better and even thrive in many cases. For every adverse or challenging experience there is a wide variation in how individuals respond: Some seem to succumb to the most minor stresses, while others seem to cope successfully with even the most terrible experiences. This ability to do well in the face of adversity is what researchers refer to as resilience (Luthar \& Cicchetti, 2000; Ungar, 2012). Originally conceptualized in terms of risk and protective factors (Werner, 1993), resilient individuals were seen to be able to manage risks due to the quantity and quality of protective factors in their lives. The risk and protective factors associated with having an LD are discussed below.

\section{Risk Factors}

Academic development. A substantial amount of literature documents the impact of an LD on students' academic development (Al-Yagon \& Mikulincer, 2004; Brazil, Cummings, \& Vallance, 1993; Daniel et al., 2006). By its very definition, learning disability implies negative academic effects, as students diagnosed with an LD are not achieving at a rate commensurate with their abilities or with the standard expectations for their age (APA, 2014). While this academic deficit is assumed to exist for all students 
with an LD, there are some studies that have specifically targeted the academic effects, such as an assumption of low-level academic functioning by teachers (Al-Yagon \& Mikulincer, 2004) and poor reading ability (Daniel et al., 2006). In addition to these studies, other literature indicates that students with an LD encounter more academic difficulties in school than their non-disabled peers and that these difficulties lead to greater risks of academic failure, school maladjustment, and high school dropout (AlYagon \& Mikulincer, 2004; Daniel et al., 2006; Wilson et al., 2009).

Mental health. Researchers have also studied mental health issues, such as anxiety, depression, and suicidality in students with an LD. The general consensus is that students with an LD exhibit more symptoms of anxiety and depression than are typically seen in the general public (Carroll \& Iles, 2006; Daniel et al., 2006; Feurer \& Andrews, 2009; Maag \& Reid, 2006). In their review of the literature on stress, depression, and suicide among students with an LD, Bender et al. (1999) concluded that students with an LD, particularly those with a nonverbal LD (NVLD) and lower academic achievement levels, showed higher rates of anxiety and depression than the general population. In addition, there seemed to be an increased risk of suicide among students with an LD. Using data from a U.S. national longitudinal study of adolescent health involving middle and high school students, Svetaz, Ireland, and Blum (2000) found that individuals with an LD were more than twice as likely as those without an LD to report emotional distress and suicide attempts. Similar rates of mental health problems were reported in a Canadian study of participants with an LD who ranged in age from 15 to 44 years (Wilson et al., 2009). The results also showed that older adults (ages 30-44) had higher rates of suicidal thoughts, depression, and distress than the younger sample (ages 15-21), thereby demonstrating that mental health problems among individuals with an LD can persist into adulthood (continuance). This finding was supported by Klassen, Tze, and Hannok (2011), whose data from a meta-analysis supported a continuance hypothesis, with rates of anxiety and depressive symptoms being similar to those found in children and adolescents. In sum, the research has demonstrated that students with an LD are at risk of experiencing academic difficulties and that individuals of all ages are at least twice as likely to have mental health problems than their non-LD peers.

\section{Protective Factors}

Individual capacities. There is a large body of resilience research on the individual capacities that serve as protective factors for individuals with an LD. Many researchers have emphasized the importance of students coming to terms with the fact that they have an LD and understanding what that means for them (Goldberg, Higgins, Raskind, \& Herman, 2003; Heiman \& Kariv, 2004; Higgins, Raskind, Goldberg, \& Herman, 2002; Kolb \& Hanley-Maxwell, 2003; Miller, 2002; Raskind et al., 2002). They have reported that the more aware students are of their LD and the strengths and challenges that come with it, the better they are able to manage. Rather than being completely defined by their diagnosis, successful individuals with an LD have been able to compartmentalize it into one aspect of their lives (Goldberg et al., 2003; Raskind, Goldberg, Higgins, \& Herman, 1999). Thus, their understanding of their LD and of themselves allows them to set realistic goals and courses of action in their lives (Heiman \& Kariv, 2004; Miller, 2002). 
A sense of control is another capacity or individual resource that emerged consistently in the literature as helping students successfully manage their LD (Freeman, Stoch, Chan, \& Hutchinson, 2004; Gerber, Ginsberg, \& Reiff, 1992; Kolb \& HanleyMaxwell, 2003). Raskind et al. (2002) contended that successful students with an LD believed that they had the power to control their destinies and to affect the outcome of their lives, and that they proactively made their own decisions and took the actions necessary to see that their decisions were realized. Focussing on decisions about goals, Hall, Spruill, and Webster (2002) found that taking the initiative to set high, yet attainable goals and working toward attaining them was a common characteristic of successful college students identified with an LD. A final individual capacity that appeared repeatedly in the literature was having a positive attitude and temperament, as this served to elicit positive responses from others and gave individuals with an LD the opportunity to take advantage of the resources in their environment (Heiman \& Kariv, 2004; Kolb \& Hanley-Maxwell, 2003; Werner, 1993).

Environmental resources. In addition to these individual capacities, there have also been a number of environmental resources that appear to facilitate positive development in students with an LD, including supportive relationships with parents, other adults, and peers. Parental support and involvement have been reported in the literature to be important resources in the lives of students with an LD (Freeman et al., 2004; Goldberg et al., 2003; Raskind et al., 1999; Reis, Neu, \& McGuire, 1997; Werner, 1993). In addition to the support provided by their parents, students with an LD have indicated that assistance from other significant people in their lives, including teachers, tutors, coaches, and friends has helped them cope (Gerber et al., 1992; Goldberg et al., 2003; Raskind et al., 2002; Werner, 1993). Teachers, who work with children and adolescents on a daily basis, can play a vital role in supporting and mentoring students with an LD. The university students interviewed by Miller (2002) reported that just knowing that their teachers believed in them and their abilities went a long way, and that the extra attention and support they provided made a difference in their lives. Private tutoring can also be an important source of support (Vogel, Hruby, \& Adelman, 1993), and college students with an LD revealed that the one-to-one relationship that they developed with their tutors had more than just an educational impact, as these tutors came to fill a number of roles, including mentor, friend, and counselor. A final facilitating resource that has been identified in the literature is friends (Freeman et al., 2004; Lee, Rojewski, Gregg, \& Jeong, 2015; Miller \& Fritz, 1998). Special friendships, even just one friend, can make a positive difference by providing students with an LD with the unconditional support and encouragement that they need (Miller, 2002). As Freeman et al. (2004) noted, friendships can also help keep struggling students connected with school when there is nothing else keeping them there.

\section{Resilience}

More recently resilience is viewed as a developmental process by which children acquire the ability to use both internal and external resources to achieve positive adaptation despite adversity (Yates, Egeland, \& Sroufe, 2003). Ungar (2012) has highlighted the importance of the dynamic and reciprocal relationship between individuals and their social and physical environments, as he conceptualizes resilience as the capacity of individuals to navigate their way to the psychological, social, cultural, and 
physical resources that sustain their well-being in the face of adversity, and the capacity, individually and collectively, to negotiate for these resources to be provided in culturally meaningful ways.

While the presence of environmental resources has been repeatedly shown to be an important source of support in the lives of students with an LD, it should be noted that the interaction between individuals and their environment is predicated on the person's willingness to accept the support when it is offered (Goldberg et al., 2003). Gerber et al. (1992) found that what distinguished highly successful adults with an LD from those who had achieved only moderate success was the amount of support available to them and their willingness to accept it. Similarly, Raskind et al. (2002) suggested that the students with an LD who had found success in life actively sought out support and were able to attract or draw support to them from key people in their environment. The literature, therefore, points to a link between the outcomes of individuals with an LD and their interaction with various environmental resources.

\section{Method}

A qualitative approach using a retrospective, multiple case study design helped us acquire an in-depth understanding of the complex social phenomenon of living with an LD and the meaning it holds for those experiencing it (Mertens, 2014; Yin, 2003). In this instance, the case study design was used to gain knowledge of the risk and protective factors identified by postsecondary students with an LD and their families and to understand how the protective factors they identified interacted to facilitate their academic and mental health resilience.

\section{Participants}

A purposeful sampling procedure was used to select this study's group of postsecondary students and their families. The intent was to assemble a group of participants that best represented the range of possibilities we were seeking to explore, so as to develop an in-depth understanding of the issues that were of central importance to this study (Glesne, 2011). In this study, the student participants were selected based on several criteria. The principal selection criterion was that they were enrolled as a student at a postsecondary institution in Ontario and that they had been formally diagnosed with an LD. The participants were restricted to Ontario students in order to ensure that they had attended and were attending similar publicly funded educational institutions within the same geographic region. It would establish that they had been identified as having an LD using comparable criteria and that the same policies and regulations shaped their educational experiences. It was also essential that at least one of the student's parents and one sibling (if they had any) were available to participate in the study so that the student, the parent, and the sibling perspectives could all be explored.

Participants were recruited through an advertisement on the Learning Disabilities Association of Ontario's website and via an email message sent to students registered with the disability services offices at two universities in Ontario. The participants included 13 individuals: 5 university students with an LD, 5 parents, and 3 siblings. The 
students with an LD were from four universities in Ontario. Demographic information for the participants is shown in Table 1.

Table 1

Demographic Information of Participants

\begin{tabular}{|c|c|c|c|c|c|c|}
\hline $\begin{array}{l}\text { Pseudo- } \\
\text { nym }\end{array}$ & Age & Family & Participants & Diagnosis & Univ. & Prog. \\
\hline Amy & 22 & $\begin{array}{l}\text { Amy } \\
\text { Mother (deceased) } \\
\text { Father } \\
2 \text { brothers }\end{array}$ & $\begin{array}{l}\text { Amy } \\
\overline{\text { Father }} \\
\text { Brother (Rick) }\end{array}$ & $\begin{array}{l}\text { Language-based LD } \\
\text { Grade } 3\end{array}$ & $\begin{array}{l}\text { Eastern } \\
\text { Ontario } \\
\text { university }\end{array}$ & BA \\
\hline Mark & 23 & $\begin{array}{l}\text { Mark } \\
\text { Mother } \\
\text { Father } \\
3 \text { brothers }\end{array}$ & $\begin{array}{l}\text { Mark } \\
\text { Mother } \\
- \\
\text { Brother (Lucas) }\end{array}$ & $\begin{array}{l}\text { Language-based LD } \\
\text { Grade } 1\end{array}$ & $\begin{array}{l}\text { Eastern } \\
\text { Ontario } \\
\text { university }\end{array}$ & BA \\
\hline Kathleen & 20 & $\begin{array}{l}\text { Kathleen } \\
\text { Mother } \\
\text { Father }\end{array}$ & $\begin{array}{l}\text { Kathleen } \\
\text { Mother } \\
\text { - }\end{array}$ & $\begin{array}{l}\text { Language-based LD } \\
\text { Kindergarten }\end{array}$ & $\begin{array}{l}\text { Eastern } \\
\text { Ontario } \\
\text { university }\end{array}$ & BA \\
\hline Paul & 20 & $\begin{array}{l}\text { Paul } \\
\text { Mother } \\
\text { Father }\end{array}$ & $\begin{array}{l}\text { Paul } \\
\text { Mother } \\
-\end{array}$ & $\begin{array}{l}\text { Nonverbal LD } \\
\text { Grade } 1\end{array}$ & $\begin{array}{l}\text { Central } \\
\text { Ontario } \\
\text { university }\end{array}$ & BA \\
\hline Krista & 32 & $\begin{array}{l}\text { Krista } \\
\text { Mother } \\
\text { Father } \\
1 \text { sister }\end{array}$ & $\begin{array}{l}\text { Krista } \\
\text { Mother } \\
- \\
\text { Sister (Kate) }\end{array}$ & $\begin{array}{l}\text { Nonverbal LD } \\
\text { Grade } 12\end{array}$ & $\begin{array}{l}\text { Central } \\
\text { Ontario } \\
\text { university }\end{array}$ & $\begin{array}{c}\text { BA } \\
\text { Master's }\end{array}$ \\
\hline
\end{tabular}

\section{Data Collection Methods}

Qualitative data were collected through individual semi-structured, in-depth interviews with postsecondary students who had been identified with an LD and their parents and siblings. These data provided an understanding of the experiences of the participants and the meaning they made of those experiences both in and out of school from multiple perspectives (Seidman, 2006). The students were interviewed three times and each participating family member was interviewed once either in their homes or at one of our offices. The individual interviews with the students lasted from 60 to 120 minutes and the ones with parents ranged from 80 to 150 minutes. Interviews with the three siblings were much shorter (20 to 30 minutes). The interviews were digitally recorded and transcribed immediately, so that ongoing analysis could occur and the participants could have the opportunity to reflect upon their responses to ensure that they accurately represented their experiences and opinions.

The interview protocols for this study were based on a synthesis of the review of the literature on learning disabilities as it relates to resilience and the associated risk and protective factors. The questions for students with an LD were designed to elicit their lived experiences as they progressed through the education system, as well as the 
capacities and resources they believe facilitated their academic and mental health resilience and their successful transition to postsecondary studies. The interview protocols for parents and siblings followed a similar pattern as for the students with an LD.

The interview process that we used was adapted from Seidman's (2006) three interview series. The first interview was used to establish a context for the participants' experiences as individuals with an LD. It explored their early life experiences, such as the initial psychological assessment and the impact that the diagnosis had on their school lives (e.g., Tell me about your school experiences. Tell me about the experience of being diagnosed with a learning disability.) The second interview focused more on the present and on the challenges they faced over the years with a special emphasis on the capacities and resources they felt helped them through these challenges (e.g., What kinds of things do you think helped you successfully graduate from high school and be accepted into university? Tell me about your experiences at university so far.). Finally, the third interview was used to provide the participants with an opportunity to reflect on the meaning of their experiences, and they were encouraged to examine how the factors in their lives interacted to bring them to their current situation (e.g., Reflecting on your school experiences as an individual with an LD, what are some of the things that helped you get to this point? Why did they help you? How do you understand yourself as a learner?).

\section{Data Analysis and Synthesis}

The data were analyzed inductively so that the findings could emerge naturally from the experiences of the participants (Seidman, 2006). Data were coded and assigned to categories that were based on Ungar's (2012) conceptualization of resilience and the risk and protective factors identified in the literature. Using the constant comparative method of data analysis, each set of interviews was completed and analyzed before moving on to the next participant (Creswell, 2012). The first step in the analysis process was to read through the data, highlighting significant text, taking notes, and writing comments in the margins. The data were then coded in order to extract and organize the key ideas into the pre-determined categories as well as create new categories that emerged. These categories were studied for common themes and connections that existed within each category and among different categories (Seidman, 2006). The themes and connections were then used to tell the stories from the perspective of the students with an LD and their families.

From this initial analysis, individual cases were created documenting the student participants' journey and the capacities and resources that were identified as having helped them along the way. Within each case, the perspectives of all the participating family members were considered and then combined in order to create a single profile. While the voices of the parents tended to be the strongest during the early years, the students' recollections became more detailed as they grew older. Unfortunately, the siblings did not have a lot of information to share, as they did not have much firsthand knowledge of the day-to-day challenges and struggles that the student participants experienced. The final step in the analysis process was to conduct a cross-case analysis to determine similarities and differences in the families' experiences and overall themes. 


\section{Trustworthiness}

In order to ensure that research is meaningful and useful to others, the knowledge it produces has to be trustworthy (Guba \& Lincoln, 1985). Two criteria were used to ensure that the study was as trustworthy as possible: credibility and transferability (Merriam, 1998.). Credibility is defined as the correspondence between the way the participants perceive social constructs and the way the researcher portrays their viewpoints (Mertens, 2014.). Member checks, the most important way of establishing credibility, were employed to seek verification with the participants about the data they provided and the researcher's interpretations (Mertens, 2014). Transferability is defined as the degree to which the reader is able to transfer or apply the findings to other situations (Mertens, 2014). In this study, measures were taken to ensure that the results were transferable, as multiple cases were used and the rich, thick descriptions of the participants' experiences allow the readers to determine how closely their situations match the research situation, and hence whether the findings can be transferred (Merriam, 1998).

\section{Findings}

\section{Case Studies}

Amy. Amy was a fourth-year university student who was working toward a double major. She is the youngest of three children and has two older brothers. Her parents both took an active role in her life, encouraging her academically and outside of school in activities like hockey and Scouts. Her mother passed away when Amy was in Grade 7, and she attributed her family to helping her through the loss. She said, "I'm pretty close with my brothers... I think my mom having cancer brought us closer than most siblings. They'd do anything for me." Her father also provided much support for Amy.

On the recommendation of her teacher, Amy was assessed in Grade 3 and diagnosed with a language-based LD. Amy looked back at the experience positively, "The diagnosis is the most important thing ... just having it laid out for you so you know that there's not something wrong with you, you're not stupid." This information helped Amy and her parents to understand her academic difficulties and the accommodations required, as well as to plan future goals. For Grades 4 and 5 she was withdrawn for language and math instruction, and in middle school she was placed in a regular classroom full-time. Unfortunately, not all of the teachers provided the accommodations to which Amy was

entitled. Her father reflected that "middle school was the one I remember the most having to go in every year and fight every year."

In high school Amy received accommodations (extra time for tests and exams, permission to write tests and exams in a quiet setting, and the use of a computer) and she learned to self-advocate. Her brother, Rick, stated, "Amy has learned to stand up for herself, and she knew what was right and wrong and spoke out when she needed help." While most of her teachers in elementary and secondary school were supportive, a guidance counsellor in high school insisted that she apply to college instead of university. As Amy had set her goal to achieve a university education, she refused and pursued the course she needed to qualify for university. She is self-motivated, hard-working, and determined, and these are qualities that have served her well both in school and in life. 
Now registered with disability services at her university, Amy brings her computer to class and reserves exam rooms in advance. She also selects courses that are of interest to her, have smaller class sizes, and are taught in a discussion style with interaction between the professor and the students, which best suits her learning style.

While enjoying the encouragement of her family and most teachers, Amy also feels supported by friends, some of whom she met in elementary school. She commented, "I'm still close with a couple of people, friends from my spec. ed. class, and then if I'm frustrated I can talk with somebody who understands it." Sports have also provided opportunities to meet new friends and develop skills, such as time management and perseverance.

Despite the risk factors associated with having an LD and the loss of her mother, neither Amy nor her father spoke of any anxiety or depression she may have experienced. It is possible that her own personality and individual capacities, coupled with the unwavering support of family, friends, and some teachers, buoyed her through difficult times. Amy now conceptualizes her LD as a difference rather than a disability. She acknowledges that she will always learn differently, but as she has matured, she has come to accept these differences.

Mark. Mark was in the final year of a social sciences program at a university close to his home. He is the youngest of four boys, and Mark's brothers range from four to eight years older than him. When Mark was young, his mother noticed that, while he was bright and talkative, he was impulsive and struggled to remember letters and numbers. As well, there were behavioural issues at school and at home. His mother recounted that the situation came to a turning point when "He told me he wanted to kill himself. He was six years old and he just said, 'I want to die. I want to kill myself."' By the end of the academic year, Mark's parents had taken him to a psychologist and he had been diagnosed with a language-based LD and ADHD. Mark reflected on the diagnosis, "It helped me to be aware of why I felt this way and why I had the challenges I had." $\mathrm{He}$ began taking medication for ADHD and believes that it helped him focus on tasks and interact more positively with his peers. Mark said,

I was probably the definition of hyperactive. I was so scattered and so wild. So I think both educationally and socially it made a big difference because I would settle down and I could focus and I could build relationships easier because I wasn't bouncing off the walls.

While Mark's behavior improved with the medication, he still struggled with reading and writing. Throughout elementary and middle school, he received assistance from the special education teachers at his schools. When he transitioned to high school he was registered for college-level courses, but when he realized that his courses needed to be at the university level to achieve his goal of working in the social sciences, he took summer courses that permitted him to enter the university stream. With the support of his parents, he began advocating for extra time and access to a special setting for tests and exams, and no penalty for spelling in his written work. Now in university, he has advocated for these same accommodations, which have helped to boost his grades. As well, taking advantage of a government work experience placement has led to an offer of employment after he graduates. 
During his educational journey, Mark received the support of his family and developed a special bond with his mother. One of his brothers commented, "My mom really helped him. She was good at encouraging him. He couldn't have done it without her." Another source of support has been his friends. Mark said, "I've lived a very privileged life to be honest. I've had a very good, close-knit group of friends that I made when I was in high school." Through his parents' response to his cry for help at age 6 and the support of teachers, friends, and others along the way, the problems Mark initially faced have not recurred. He now views his LD as a learning difference and just part of who he is, and he is eager to graduate and begin the next phase of his life.

Kathleen. An only child, Kathleen was diagnosed with epilepsy at age 3 and an LD three years later. When diagnosed with the LD, her parents openly discussed her strengths and weaknesses with her, and have continued to do so over the subsequent years. She was re-assessed at the age of 16, and she reflected that the psychologist's explanation of the diagnosis reinforced that she was "smart... and it let me know that I have to work harder than someone else." In elementary school Kathleen was withdrawn to the special education classroom every day and she worked with an occupational therapist and a speech therapist. By middle school she was placed in a regular classroom with accommodations (extra time on tests, the opportunity to write tests in a quiet place, and the use of a computer). Although she reports that she did not have any friends, she did participate in summer camps and various sports activities, which helped develop her social skills and improve her self-confidence. For several years she was bullied by a peer, but her mother documented the daily harassment and worked with the school to ensure that the girls were separated and that Kathleen was supported by her teachers.

The summer before Kathleen began high school, her mother developed cancer and was in the midst of treatment when classes began. While trying to deal with her mother's illness, Kathleen was also forced to assume full responsibility for her school work. Her mother recalled that Kathleen went through "a really, really tough time." Kathleen spoke about that difficult period: "I didn't really have anyone to help with this. I remember I was so mad because everyone kept asking how my mom was but no one asked me how I felt." Her parents arranged for Kathleen to see a psychologist to help her understand and manage some of the emotions she was experiencing. In time, she was able to focus on her school work, and her mother helped with homework once she had recovered. During high school Kathleen made some friends and is still close to one or two of them. She stated, "When I struggle with school or whatever, I know I can [go to them] and if I need immediate attention, I just talk to my friends.... I know these people will help me through it."

Although Kathleen wanted to study social sciences at university, she and her parents decided that she would try college first. Unfortunately, there was no academic support available to her at the college she attended, and laptops were not permitted in the classroom. She found that she wasn't learning much and when she failed a practicum, the decision was made to leave college and apply to university. She was accepted, and after registering with the disability services office she received the accommodations she required. She is now completing an undergraduate degree and is considering pursuing graduate studies. 
Kathleen feels that her LD is a learning difference and she accepts that she has to work harder than her peers to reach her academic goals. However, she is disheartened by the stigma attached to LDs. She commented, "It's kind of like a mental disease. People don't get it because they can't see it." While she encountered academic difficulties due to her LD and went through some difficult times when her mother was sick, the support she received from her family, friends, and counselling helped her persevere and manage the challenges she faced.

Paul. From an early age, Paul knew he wanted to make movies, and he was determined to go to a university for a film studies program. However, his journey to postsecondary education was not without challenges. Paul's Grade 1 teacher recommended that he be referred for a psychological assessment, and the results showed that while his abstract thinking and reasoning skills approached the gifted range, he had a nonverbal LD (NVLD). His mother openly and fully discussed the results with him, and he felt that they explained some of the challenges he was experiencing. Throughout the elementary grades, Paul was withdrawn for special education support in language and math. However, it was the difficulties he had interacting with his peers that seemed to cause even greater challenges for him. His mother recalled that Paul "was always bullied, and he was always bullied by even the kids who weren't popular. He was at the bottom." During this period, his parents separated, and it was a challenging time for him. He began seeing a psychologist who helped him understand what was happening and work through some of the emotions he was experiencing.

Middle school marked a positive turning point in Mark's life, as his mother found an appropriate placement for him at an alternative school where teachers used a childcentred approach. He began to make some friends and was no longer bullied. Paul stated,

There was just a whole bunch of us who were bullied in elementary school, so we just kind of felt really threatened and kind of sought each other out and formed such a big group that no one bothered us.

At this school he had accommodations, such as extra time and a special setting for tests and the use of a computer for his school work. He later undertook the lengthy process of applying to a high school dedicated to the arts and was accepted into one of their programs. The accommodations were maintained, and he had the assistance of a resource teacher who helped him stay organized. Academically, Paul worked hard and graduated on the principal's honour roll. Socially, Paul was the only one from his group of friends from middle school who went to this high school, and it took him a few months to open up to others. He explained, "I was still just really nervous about other people and put up walls and really isolated myself." As he matured, Paul learned the social conventions he needed to fit in, and he developed some friendships in high school that have endured to this day.

Now in a film studies program at a university a few hours from home, he is registered with the disability services office, self-advocates for the accommodations he needs, takes his computer to class, and has extra time to write exams. Paul described himself as "incredibly disorganized" and commented, "It's cost me a lot of money in things that I've lost. It's cost me marks. It's cost me a lot of things." During the summers he has been employed on a film set and in a production office for a television show. 
Throughout his educational journey, Paul's mother has provided emotional, financial, organizational, and academic support for her only child. To develop his social skills, interest in sports, and talents in the arts, she registered him in many extracurricular activities when he was younger. Paul is very aware of the important role his mother has played in his life: 'I'm glad I've got the support I have and I don't think I would have gotten this far without it." He sees himself as intelligent and creative, and he views his LD as a different way of learning and thinking, which he feels has turned out to be a gift.

Krista. Krista was a graduate student working on a Master's degree who was only diagnosed with her NVLD when she was in Grade 12. As a child, Krista's mother noticed that her younger daughter did not seem to understand the social conventions that most people took for granted, and her sister added that she could not "name any of the kids that she was really best friends with or anything." Krista commented that she was "confused" about social relations and reflected that her sister, who was older by seven years, "would look after me and she would kind of direct me if I was not sure about something or I needed help with a social situation or how to do school work." But the social awkwardness caused Krista to feel uncomfortable at school. She missed a lot of school due to stomach aches and other complaints. In retrospect, she sees it as a kind of anxiety and wonders why more was not made of it at the time. Her mother, however, never connected anxiety to any of Krista's physical complaints. It was also at this time that her parents separated and Krista moved with her mother and older sister into the city.

In elementary and middle school, Krista's achievement was commensurate with her peers, except in math, but she received no extra assistance in this subject. When she reached high school, she found that the academic demands increased, and she had to spend considerably more time on homework and studying than her peers. In Grade 10, she stopped socializing so that she could spend all her time on school work. Krista explained, "I had to make [a] choice, so I was more focused on school ... it was too exhausting to take the energy to go and socialize." As well, she sought help from a resource teacher at the school and spent her spare period working on math with him. In Grade 11, math continued to be a challenge; and even with her hard work and assistance from the resource teacher, she failed the course and had to go to summer school. Krista also reported that she had difficulty organizing and expressing her thoughts in written form, and she became increasingly frustrated by her low marks, despite many hours of work and assistance from her mother.

During the summer before Grade 12, Krista worried that she might not graduate with her peers, and it prompted her and her mother to discuss the situation with her aunt, who was a psychologist. A psychological assessment was arranged, and Krista was diagnosed with a NVLD. Unlike the other families, Krista and her mother did not fully accept the diagnosis initially. Krista was upset about being diagnosed with an LD while her mother recalled feeling "devastated because I thought I should have known long before ... It's awfully hard to see that there's something wrong with your child." The results were shared with the school, and accommodations were arranged for Krista: extra time on examinations, a quiet place to write examinations, and the use of a laptop. However, Krista had to self-advocate with each teacher to obtain the accommodations, and this was difficult for her. In hindsight, Krista believed that she might have been experiencing periods of depression as she reflected, 
I wonder about depression when I was a kid and when I was in high school because I was really, really pessimistic and just had a negative outlook on things. And not feeling really happy about stuff because you're just focussing on work and there's just anxiety about everything.

During Grade 12, Krista applied to a university less than an hour from home and was accepted. She had the same accommodations as in high school, and she continued to rely on her mother and sister to edit her assignments. However, despite the long hours of studying, she could not seem to memorize material for exams and did not receive the marks she expected. Krista said that she was "angry about school in general" because when she compared herself to her peers she "always came up short, so I didn't want to be involved with them." She coped by isolating herself so that no one would know how she felt. Despite these challenges, in her third year at university she made a connection with a student who had similar types of experiences, and they provided each other with emotional support. Around this same time, Krista transferred to another department and then graduated the following year.

After graduation, Krista worked both abroad and in Ontario for the next five years. She did not disclose her LD to her employers, and she grew to dislike the work as she stated, "Everyday going in [to work] was like a complete misery." She decided to return to university and was admitted into a Master's program where she received accommodations and enjoyed her courses. As a result of information gleaned from some of her assignments, Krista came to believe that the anxiety and depression she felt in high school and university are likely linked to her NVLD, and she has become more accepting of her own disability. She has connected with other people who have disabilities and has shared her own difficulties with them. With the help of her aunt and with the financial assistance of her mother, Krista has also hired a disabilities coach who helps her work through any challenges she encounters in her life and recommends strategies to manage the situations. As a result, Krista now feels more in control and is not so overwhelmed. She is still uncomfortable with the label, disability, because it suggests a deficit. However, she now acknowledges that the label was important, "When you've got it [the label], you know where to start and you can start figuring things out and you know what kinds of things you can do." She no longer sees her NVLD as a deficit or a disability, but views it as a difference.

\section{Discussion}

The purpose of this research was to examine the lived experiences of five postsecondary students who had been diagnosed with an LD and those of their families in order to identify the capacities and resources that helped them on their educational journeys. While each participant's story was unique, the overarching path of their journeys revealed a number of common themes, including: (a) the presence of early academic and socio-emotional challenges; (b) the importance of early diagnosis and intervention; (c) common family characteristics and family support; (d) the development of self-awareness, self-acceptance, and self-advocacy over time; (e) the importance of goal setting and determination; and (f) the important and complex role of social support. Each of the themes will be discussed in turn and identified as either a risk or a protective factor. 


\section{Risk Factors}

Academic and socio-emotional challenges. All five students were diagnosed with an LD - three had a language-based LD, while the remaining two had an NVLD. In school, the LDs were manifested in the participants' difficulties with language and math, and in two cases problems with written work continued into university. Four of the participants were diagnosed with an LD early in life, and they were withdrawn for special instruction for at least part of the day in elementary school. They also had accommodations throughout high school and university. While Krista was not diagnosed until Grade 12, she advocated for formal accommodations during her final year of high school and like the others, she received them while in university. In sum, similar to findings reported elsewhere, the student participants' LDs were associated with academic challenges (Al-Yagon \& Mikulincer, 2004). However, in contrast to other research (Daniel et al., 2006), these participants demonstrated academic resilience as they have all completed high school and are on track to graduate from a university program.

In addition to academic problems in elementary school, Kathleen and Paul also recounted social difficulties when they were younger, and both reported times when they were bullied by their peers. Their parents took action to remedy the situations, however, and both improved with time. While not bullied, Mark experienced some early social and behavioural difficulties in kindergarten and Grade 1, engaging in temper tantrums both at home and at school. When he talked about killing himself, his parents sought help from a psychologist, and Mark was diagnosed at the age of 6 with an LD and ADHD. He began taking medication for his ADHD and this helped to improve his social and behavioural situation. Kathleen's and Paul's parents also sought the help of a psychologist when their children had difficulty dealing with life events: Paul had difficulty when his parents separated, and Kathleen found it emotionally challenging to begin high school without the support of her mother, who was undergoing cancer treatments. Amy also went through some difficult times in middle school when her mother passed away from cancer, but her family members did not seek outside assistance for the children. Although not diagnosed or treated when she was a child, Krista feels that she may have experienced bouts of anxiety and depression throughout her life, but she is learning to manage these feelings now with the help of her disability coach. Thus, while life events had an impact on all of the participants, they were able to work through them with the support of their families and in some cases professional counselors, therapists, or coaches.

\section{Protective Factors}

Early diagnosis and intervention. Once parents were aware of the challenges their children were facing, most of them acted quickly to determine what the problem was and how they could help. Consequently, Amy, Mark, Kathleen, and Paul were each tested and diagnosed with an LD before the third grade. Because of this early diagnosis, all four of them received specialized support from the special education teachers at their schools, and individual education plans were created to ensure that they received the accommodations that they needed. These findings are consistent with the LD literature which has established that early identification and intervention is one of the key factors in 
children's successful development (Litner, Mann-Feder, \& Guerard, 2005; Shaywitz, 2003; Winzer, 2007).

This ability to identify academic challenges and implement the appropriate supports and interventions early in students' lives is predicated on good communication and interaction between home and school. Parents need to be actively involved in their children's lives so that they are aware of any challenges they are facing, and teachers need to be invested in their students so that they can detect when they are struggling and showing some of the early signs of an LD. This study revealed that it was the interactions that occurred between the home and the school, particularly teachers who recommended an assessment, that led to parents' seeking and accessing help for their children.

Family characteristics and parent support. All of the students reported that they spent a lot of time with their families when they were growing up and that their parents were an important source of support in their lives. After receiving their children's diagnoses, the parents in this study educated themselves so that they could advocate for their children and ensure that the appropriate accommodations were in place at school. Parents also provided support for their children in the home by helping with their homework and arranging for additional tutoring in the community when necessary. Krista's mother helped her daughter with her homework throughout her education, but she did not seem to become aware of the severity of her struggles and frustrations until Krista's final years in high school. Additional academic support was provided by Krista's sister, who assisted with assignments and along with her mother continued to edit essays during the university years. While none of the other siblings helped the participants with an LD with their academic assignments, some did provide emotional support. Additionally, none of the siblings expressed jealousy about the time their parents spent tutoring and supporting their sibling with an LD, which is consistent with Dyson's (1996) research.

Social support. The importance of peer support and friendships is well documented in the literature by researchers such as Freeman et al. (2004) and Miller (2002). Most of the students in the current study have come to identify friends as their primary source of emotional support. This situation was not always the case, however, as these relationships developed over time. Friendships have become very important to the students, and consequently their friends are an important source of support in their lives, taking over the role that their families filled when they were younger. Krista did not begin developing friendships until she was in university and seemed to withdraw from peers when she was under academic pressure. Hence, unlike the other four participants, Krista relied primarily on her mother and sister for emotional support and has not enjoyed the extra support that could be provided by a social network until more recently.

Another source of support that may be tapped is significant others (Higgins et al., 2002). Teachers were an important source of assistance for Amy, Mark, and Paul. It was teachers who recommended a psychological assessment to Amy's and Paul's parents, and their early diagnosis was in part due to the willingness of teachers to approach parents with their observations and recommendations. These three participants also had a few teachers who understood LDs, demonstrated care, and went out of their way to help them (Miller, 2002). Krista benefitted from a resource teacher in high school who assisted her with math, even though she had not been diagnosed with an LD at that time. However, 
some of her teachers did not appear to recognize the academic and social challenges that she was experiencing. Krista's mother might have obtained a psychological assessment for her daughter earlier if a teacher had discussed these concerns or the many absences from school with her. Krista was fortunate to have two significant others who provided assistance: her aunt, who arranged for the psychological assessment in Grade 12; and the disability coach she recently hired, who listens to her problems and provides suggestions and support.

In summary, the participants with an LD in this research had many interpersonal supports during their educational journeys. As shown in other studies, parents and siblings provided the most intense and continuous source of support for all of the participants (Goldberg et al., 2003; Lee et al., 2015; Reis et al., 1997), and friends became an important factor as the participants grew older (Heiman \& Kariv, 2004; Miller, 2002). Significant others, such as teachers and extended members of the family also occasionally provided support (Werner, 1993).

Goal setting and determination. Initially it was the parents who set goals for their children and worked with them in order to achieve them; but as they grew older, the students began to assume more of this responsibility. Through their ongoing interactions and by observing what their parents had done, the students developed these goal setting skills themselves. All of the students knew that they wanted to attend university from a young age, and they all worked hard toward achieving this goal, despite setbacks and challenges they encountered along the way. They took it upon themselves to ensure that they had the required high school courses to be admitted into their chosen programs. They worked hard, persevered, self-advocated for accommodations, and managed the transition process to university in order to reach their goal. Their perseverance and willingness to work through challenges was nurtured through the active support they received from their parents. The development of these individual capacities is supported by the research of Freeman et al. (2004) and Hall et al. (2002), which emphasized the importance of having a "goal orientation" or "goal directed" approach to life for students with LDs.

Development of self-awareness, self-acceptance, and self-advocacy in students over time. While it was important for the parents in this study to support and advocate for their children when they were younger, it was also important that they help their children develop these skills themselves so that they could self-advocate as they matured. By communicating openly with them about their LDs, parents helped their children develop an authentic understanding of themselves as learners, which later supported them in becoming advocates for their own needs. To perform this role, the parents required an accurate understanding of their children's LDs themselves. The parents in the current study educated themselves by talking with professionals, by reading books and materials from LD associations, and by accessing websites. They then shared this knowledge with their children as it was appropriate. This awareness allowed the students to accept themselves and their learning challenges over time, and it made them more comfortable sharing this information with others. Like their parents, most of the participants accepted the diagnosis and began to see their LD as part of who they were, reframing it as a "difference" rather than a disability - Paul even referred to his LD as a gift (Gerber et al., 1992). Krista, who was diagnosed later in life, did not develop this self-awareness and understanding as quickly as the other student participants, and consequently she struggled 
more than the others to accept her LD. When she finally began to come to terms with it, she seemed to find comfort in her increased awareness and was empowered by her understanding and knowledge of LDs.

In addition to building their self-awareness and self-acceptance of LDs, the parents in this study helped develop self-advocacy skills in their children with LDs through modelling. The students saw their parents working with their teachers and speaking on their behalf when they felt that their children were not receiving the support or understanding they deserved. This responsibility gradually shifted from parents to children, and the students began to use these skills themselves to advocate on their own when they were older (Fullarton \& Duquette, 2015). Without an accurate understanding of their LD and without an acceptance of themselves as individuals with an LD, they would likely not have been able to take over this responsibility. The importance of self-awareness and acceptance of the diagnosis in students with an LD and the critical role that selfadvocacy can play in the development of students with LDs has been well demonstrated in the literature (Goldberg et al., 2003; Heiman \& Kariv, 2004; Higgins et al., 2002; Kolb \& Hanley-Maxwell, 2003; Litner et al., 2005; Miller, 2002; Raskind et al., 2002).

\section{Facilitating Resilience}

Guiding this study was Ungar's (2012) conceptualization of resilience as the capacity of individuals to navigate their way to the environmental resources they need to sustain their well-being. It was demonstrated that individual capacities were nurtured and developed by families, teachers, friends, and community members so that the students with an LD were able to obtain the supports and resources they required, thereby helping them to manage the potential risk factors of school failure and mental health problems. The individual capacities that led to resilience were self-goal setting, determination, selfawareness, self-acceptance, and self-advocacy. In this study, parent modelling of awareness, acceptance, and advocacy supported the development of these capacities within their children. In four of the five cases the students developed all the above capacities by adolescence and were able to access academic resources on their own. As well, early in the lives of three students, it was the parents demonstrating awareness and acceptance of emotional difficulties that helped mitigate potential mental health problems.

Krista's situation was different in that awareness, acceptance, and advocacy were not modelled for her early on. Yet, she was able to develop the capacity to self-advocate and obtain the accommodations she required to pass her courses in both high school and university. However, unlike the other students, Krista's emotional challenges were not recognized and addressed in childhood and adolescence, and she recalled experiencing anxiety and depression-like symptoms at various times in her life. It was only as an adult in her thirties that, with the help of family, she was able to obtain the resources she needed to ease the anxiety she felt in managing the stresses of daily life. Unlike the other three students, Krista sought the help of a disabilities coach instead of a mental health professional. As well, with the support of friends and peers she was able to develop the individual capacity of self-acceptance, which may have influenced her decision to access resources outside of her family. 


\section{Limitations}

Several limitations must be acknowledged. In this retrospective study the participants were asked to share their memories, which may have been influenced or shaped by other experiences they had over time (Clandinin \& Connelly, 2000), and they may have interpreted past events from their present perspectives (Freeman, 2004). A second limitation is that only university students with LDs and their families were interviewed. No college students or young adults who had transitioned to employment participated in this study, and hence their experiences were not included. Thirdly, all of the participants with an LD came from close-knit, supportive families in which the parents had the capacities and resources to obtain the supports required for their children. The parents also had positive relationships with the elementary and secondary school staff, which is not always the case. Incorporating different family situations and perspectives would have added more breadth and depth to the findings. A fourth limitation is that not all of the participants with an LD had siblings, and those brothers and sisters who did participate did not have many memories of their siblings' experiences. Therefore, in this research, the perspectives of brothers and sisters did not shed much light on the experiences of their siblings with an LD. A final limitation is that there was no input from teachers or professors. This dimension would have added to the research, as teachers have the opportunity to see children in different settings than their parents do.

\section{Conclusion}

This research on resilience revealed how a supportive environment facilitated the development of the individual capacities required by students with an LD in order to access the academic and mental health supports that they needed. Although it took time, Krista learned to negotiate for these resources and supports on her own. While she learned to self-advocate for the academic supports and accommodations she needed in high school, she only began to self-advocate for the mental health supports she needed when she was in her thirties. It is possible that a greater awareness of LDs and mental health issues on the part of her teachers in elementary school might have led to an earlier diagnosis of NVLD and the provision of the academic and mental health resources to address her needs. An implication for teachers is the need for mental health training, in order that they may recognize the symptoms, assuage the concerns about stigma, and assist parents or students in obtaining the resources they need (Harŏardóttir, Júlíusdóttir, \& Guŏmundsson, 2015; Whitley, Smith, \& Vaillancourt, 2012). Ungar (2012) contended that switching the focus from changing individual behaviours to improving the availability of resources within the community may facilitate resilience. Additionally, this study found that developing the capacity within an individual to access these resources requires the support of family, friends, and society in general.

Future research might extend this research by following individuals with an LD as they transition from university to their working lives. The students in this study demonstrated resilience in the academic world by accessing the resources they required in that environment. By seeking support in their place of employment and making use of them, they may be able to make their work environment a good fit for them as well (Gerber et al., 1992) and extend their resilience into the next phase of their lives. 


\section{References}

Al-Yagon, M., \& Mikulincer, M. (2004). Patterns of close relationships and socio-emotional and academic adjustment among school-age children with learning disabilities. Learning Disabilities Research and Practice, 19, 12-19. doi:10.1111/j.15405826.2004.00085.x

American Psychiatric Association. (2013). Diagnostic and statistical manual of mental disorders (5th ed.). Arlington, VA: Author.

Bender, W., Rosenkrans, C., \& Crane, M. (1999). Stress, depression, and suicide among students with learning disabilities: Assessing the risk. Learning Disability Quarterly, 22, 143-156. doi: $10.2307 / 1511272$

Brazil, K., Cummings, R., \& Vallance, D. (1993). Mental health needs of children and youth with learning disabilities: Overview of a community needs assessment. Evaluation and Program Planning, 16, 193-198. doi:10.1016/0149-7189(93)90003-Q

Carroll, J., \& Iles, J. (2006). An assessment of anxiety levels in dyslexic students in higher education. British Journal of Educational Psychology, 76, 651-662. doi:10.1348/000709905X66233

Clandinin, J., \& Connelly, M. (2000). Narrative inquiry: Experience and story in qualitative research. San Francisco, CA: John Wiley and Sons.

Creswell, J. (2012). Qualitative inquiry and research design: Choosing among five approaches (3rd ed.). Thousand Oaks, CA: Sage Publications.

Daniel, S., Walsh, A., Goldston, D., Arnold, E., Reboussin, B., \& Wood, F. (2006). Suicidality, school dropout, and reading problems among adolescents. Journal of Learning Disabilities, 39, 507514. doi:10.1177/00222194060390060301

Dyson, L. (1996). The experiences of families of children with learning disabilities: Parental stress, family functioning, and sibling self-concept. Journal of Learning Disabilities, 29, 280-286. doi:10.1177/002221949602900306

Feurer, D., \& Andrews, J. (2009). School-related stress and depression in adolescents with and without learning disabilities: An exploratory study. The Alberta Journal of Educational Research, 55, 92-108. Retrieved from http://www.ajer.ca

Freeman, J., Stoch, S., Chan, J., \& Hutchinson, N. (2004). Academic resilience: A retrospective study of adults with learning difficulties. The Alberta Journal of Educational Research, 50, 5-21. Retrieved from http://www.ajer.ca

Freeman, M. (2004). Data are everywhere: Narrative criticism in the literature of experience. In C. Daiute \& C. Lightfoot (Eds.), Narrative analysis: Studying the development of individuals in society (pp. 63-81). Thousand Oaks, CA: Sage Publications.

Fullarton, S., \& Duquette, C. (2015). The transition process for adolescents with learning disabilities: Perspectives of five families. Exceptionality Education International, 25, 84-106.

Gerber, P., Ginsberg, R., \& Reiff, H. (1992). Identifying alterable patterns in employment success for highly successful adults with learning disabilities. Journal of Learning Disabilities, 25, 475487. doi:10.1177/002221949202500802

Glesne, C. (2011). Becoming qualitative researchers: An introduction (4th ed.). Boston, MA: Pearson Education.

Goldberg, R., Higgins, E., Raskind, M., \& Herman, K. (2003). Predictors of success in individuals with learning disabilities: A qualitative analysis of a 20-year longitudinal study. Learning Disabilities Research and Practice, 18, 222-236. doi:10.1111/1540-5826.00077 
Hall, C., Spruill, K., \& Webster, R. (2002). Motivational and attitudinal factors in college students with and without learning disabilities. Learning Disability Quarterly, 25, 79-86. doi: $10.2307 / 1511275$

Harŏardóttir, S., Júlíusdóttir, S., \& Guŏmundsson, H. (2015). Understanding resilience in learning difficulties: Unheard voices of secondary school students. Child and Adolescent Social Work Journal, 32, 351-358. doi:10:1007/s10560-014-0373-1

Heiman, T., \& Kariv, D. (2004). Manifestations of learning disabilities in university students: Implications for coping and adjustment. Education, 125, 313-324. Retrieved from http://www.projectinnovation.biz/index.html

Higgins, E., Raskind, M., Goldberg, R., \& Herman, K. (2002). Stages of acceptance of a learning disability: The impact of labeling. Learning Disability Quarterly, 25, 3-17. doi: $10.2307 / 1511187$

Klassen, R., Tze, V., \& Hannok, W. (2011). Internalizing problems of adults with learning disabilities: A meta-analysis. Journal of Learning Disabilities, 46, 317-327. doi:10.1177/0022219411422260

Kolb, S., \& Hanley-Maxwell, C. (2003). Critical social skills for adolescents with high incidence disabilities: Parental perspectives. Exceptional Children, 69, 163-179. Retrieved from http://www.cec.sped.org

Learning Disabilities Association of Canada (LDAC). (2007). Prevalence of learning disabilities. Retrieved from www.ldac-taac.ca/learn-more/prevalence-of-lds/prevalence-oflearning disabilities.html

Lee, H., Rojewski, J., Gregg, N., \& Jeong, S. (2015). Postsecondary education persistence of adolescents with specific learning disabilities or emotional behavioral disorders. The Journal of Special Education, 49, 77-88. doi:101177/0022466914524826

Litner, B., Mann-Feder, V., \& Guerard, G. (2005). Narratives of success: Learning disabled students in university. Exceptionality Education Canada, 15, 9-23.

Luthar, S., \& Cicchetti, D. (2000). The construct of resilience: Implications for interventions and social policies. Development and Psychopathology, 12, 857-885. doi:10.1017/S0954579400004156

Maag, J., \& Reid, R. (2006). Depression among students with learning disabilities: Assessing the risk. Journal of Learning Disabilities, 39, 3-10. doi:10.1177/00222194060390010201

Merriam, S. (1998). Qualitative research and case study applications in education. San Francisco, CA: John Wiley and Sons.

Mertens, D. (2014). Research and evaluation in education and psychology: Integrating diversity with quantitative, qualitative, and mixed methods (4th ed.). Thousand Oaks, CA: Sage Publications.

Miller, M. (2002). Resilience elements in students with learning disabilities. Journal of Clinical Psychology, 58, 291-298. doi:10.1002/jclp.10018

Miller, M., \& Fritz, M. (1998). A demonstration of resilience. Intervention in School and Clinic, 33, 265-271. doi:10.1177/105345129803300502

Raskind, M., Goldberg, R., Higgins, E., \& Herman, K. (1999). Patterns of change and predictors of success in individuals with learning disabilities: Results from a twenty year longitudinal study. Learning Disabilities Research and Practice, 14, 35-49. doi:10.1207/sldrp1401_4

Raskind, M., Goldberg, R., Higgins, E., \& Herman, K. (2002). Teaching "life success" to students with LD: Lessons learned from a 20-year study. Intervention in School and Clinic, 37, 201208. doi:10.1177/105345120203700402

Reis, S., Neu, T., \& McGuire, J. (1997). Case studies of high-ability students with learning disabilities who have achieved. Exceptional Children, 63(4), 463-479. doi:10.1177/001440299706300403

40 Exceptionality Education International, 2016, Vol. 26, No. 2 
Schram, T. (2006). Conceptualizing and proposing qualitative research (2nd ed.). Upper Saddle River, NJ: Pearson Education.

Seidman, I. (2006). Interviewing as qualitative research: A guide for researchers in education and the social sciences (3rd ed.). New York, NY: Teachers College Press.

Shaywitz, S. (2003). Overcoming dyslexia: A new and complete science-based program for reading problems at any level. New York, NY: Vintage Books.

Svetaz, M., Ireland, M., \& Blum, R. (2000). Adolescents with learning disabilities: Risk and protective factors associated with emotional wellbeing: Findings from the National Longitudinal Study of Adolescent Health. Journal of Adolescent Health, 27, 340-348. doi:10.1016/S1054-139X(00)00170-1

Ungar, M. (Ed.). (2012). The social ecology of resilience: A handbook of theory and practice. New York, NY: Springer.

Vogel, S., Hruby, P., \& Adelman, P. (1993). Educational and psychological factors in successful and unsuccessful college students with learning disabilities. Learning Disabilities Research and Practice, 8, 35-43.

Werner, E. (1993). Risk and resilience in individuals with learning disabilities: Lessons learned from the Kauai longitudinal study. Learning Disabilities Research and Practice, 8, 28-34. Retrieved from http://onlinelibrary.wiley.com

Whitley, J., Smith, D., \& Vaillancourt, T. (2012). Promoting mental health literacy among educators: Critical in school-based prevention and intervention. Canadian Journal of School Psychology, 28, 56-70. doi:10.1177/0829573512468852

Wilson, A., Deri Armstrong, C., Furrie, A., \& Walcot, E. (2009). The mental health of Canadians with self-reported learning disabilities. Journal of Learning Disabilities, 42, 24-40. doi:10.1177/0022219408326216

Winzer, M. (2007). Children with exceptionalities in Canadian classrooms (5th ed.). Toronto, ON: Pearson.

Yates, T., Egeland, B., \& Sroufe, L. (2003). Rethinking resilience: A developmental process perspective. In S. Luthar (Ed.), Resilience and vulnerability: Adaptation in the context of childhood adversities (pp. 243-266). New York, NY: Cambridge University Press.

Yin, R. (2003). Case study research: Design and methodology (3rd ed.). Thousand Oaks, CA: Sage Publications.

\section{Authors' Note}

Lisa Piers is now at the Ottawa Carleton District School Board, Ottawa, ON.

Correspondence concerning this article should be addressed to Cheryll Duquette, Faculty of Education, University of Ottawa, Ottawa, ON, K1N 6N5, Canada. Email: cduquett@uottawa.ca 